\title{
Drug and alcohol addiction: new pharmacotherapies
}

\author{
Jason Luty
}

\begin{abstract}
SUMMARY
Over the past decade, important research has been performed into the therapeutic use of dihydrocodeine, injectable opioids (diamorphine) and supervised disulfiram in addiction treatment. There have also been interesting developments regarding baclofen for alcohol problems and use of stimulants in adult Attention-deficit hyperactivity disorder (ADHD). However, evidence for the effectiveness of medication to promote alcohol abstinence remains modest at best.
\end{abstract}

\section{LEARNING OBJECTIVES}

- Develop awareness of risks of diversion when considering prescribing drugs of misuse such as stimulants for ADHD, morphine and injectables to treat addiction

- Update information on newer treatments of opioid dependence, especially the buprenorphinenaloxone combination

- Refresh information on treatment of alcohol misuse and dependence, especially supervised disulfiram and opioid antagonists

\section{DECLARATION OF INTEREST}

None

This is the second of a group of articles updating reviews of substance misuse treatment published in Advances around a decade ago (Luty 2003, 2006). I reviewed new challenges in addiction treatment in my previous article (Luty 2014). The present article concerns new pharmacological treatments and a future review will consider psychosocial treatments.

Specialist treatment for heroin addiction works. For example, a large multisite study in Italy found that the mortality for heroin users out of treatment was approximately ten times higher than for those in treatment, regardless of the type of treatment received (Davoli 2007). Despite political preferences for abstinence-based treatments, longterm maintenance treatment (typically methadone maintenance) has consistently been shown to be more effective. Unfortunately, abstinence-based treatments are the only options for many addictive disorders, especially alcohol and stimulant misuse.
Methodological issues in addictions research could occupy several review articles. It is notable that there remains no consensus on outcome measures for the effectiveness of alcohol treatment. Many programmes have traditionally focused on abstinence, in which case the time to first relapse (e.g. the consumption of more than five UK standard drinks or $40 \mathrm{~g}$ of alcohol in $24 \mathrm{~h}$ ) is an appropriate measure. However, in practice, the number of drinking days over a given period is probably more relevant, especially if a 'relapse' only lasts for 1 day (see for example the nalmefene trial by Mason et al discussed below). A more objective measure would be levels of serum gamma-glutamyl transferase (GGT), which can be shown to fall with successful treatment (de Sousa 2005). Reviewers also have to assiduously discriminate between trials that recruit problem drinkers (which can have relatively good outcomes) and dependent drinkers (who are much more treatment refractory). Similarly, there is often a distinction in outcomes between trials that recruit patients directly from the community (who tend to have better outcomes) and those that recruit clinical populations or 'treatment-seeking' patients (who are often more refractory). There is also an increasing recognition that the evidence base can be distorted by selective publication, recruitment of atypical patient groups and financial vested interests (trials funded by the pharmaceutical industry).

\section{Opioid dependence}

Table 1 outlines the pharmacokinetics of some commonly used (and misused) opioids.

\section{Buprenorphine-naloxone combination}

Buprenorphine is now widely used in treatment of opioid dependence (Department of Health (England) 2007). Buprenorphine implants have also become available, although it is unclear whether these have any advantage over sublingual formulations. A buprenorphine-naloxone combination has also been introduced in the UK, as Suboxone ${ }^{\circledR}$. Buprenorphine-naloxone sublingual film has not yet been introduced in the UK but is likely to be launched in 2015 .
Jason Luty is consultant in addictions psychiatry at Borders Health in Scotland. He trained at the Maudsley Hospital, London, and spent 8 years as consultant in addictions at the South Essex Partnership University NHS Foundation Trust, England. He has a $\mathrm{PhD}$ in pharmacology following a study of the molecular mechanisms of receptor desensitisation and tolerance and has published in the addictions field. Correspondence Dr Jason Luty, Borders Addiction Service, The Range, Tweed Road, Galashiels TD1 3EB, Scotland. Email: jason.luty@yahoo.co.uk 
TABLE 1 Pharmacokinetics of some commonly used (and misused) opioids

\begin{tabular}{|c|c|c|c|c|c|}
\hline Drug & Approximate half-life & Active routes & Bioavailability & Excretion & Metabolism \\
\hline Morphine & $2-3 h$ & $\begin{array}{l}\text { Inhalation (smoking), insufflation } \\
\text { (snorting), oral, rectal, } \\
\text { subcutaneous, intramuscular, } \\
\text { intravenous, epidural, intrathecal }\end{array}$ & $\begin{array}{l}20-40 \% \text { (oral), } \\
36-71 \% \text { (rectal), } \\
100 \% \text { (intravenous or } \\
\text { intramuscular) }\end{array}$ & $\begin{array}{l}\text { Renal } 90 \% \text {, } \\
\text { biliary } 10 \%\end{array}$ & Hepatic 90\% \\
\hline Buprenorphine & $\begin{array}{l}30 \mathrm{~h} \text { (topical/sublingual) } \\
1-7 \mathrm{~h} \text { intravenous }\end{array}$ & $\begin{array}{l}\text { Sublingual, injection, insufflation, } \\
\text { transdermal }\end{array}$ & $\begin{array}{l}55 \% \text { (sublingual), } 40-55 \% \\
\text { (intranasal) }\end{array}$ & $\begin{array}{l}\text { Renal } 30 \% \text {, } \\
\text { biliary } 70 \%\end{array}$ & Hepatic \\
\hline Heroin, diamorphine & $<2-3 \min$ & $\begin{array}{l}\text { Inhalation, insufflation, oral, rectal, } \\
\text { subcutaneous, intramuscular, } \\
\text { intravenous, epidural, intrathecal }\end{array}$ & $\begin{array}{l}<35 \% \text { (oral), } 44-61 \% \text { (inhaled), } \\
0 \% \text { subcutaneous, intramuscular, } \\
\text { intravenous }\end{array}$ & $\begin{array}{l}\text { Renal } 90 \% \text {, } \\
\text { biliary } 10 \%\end{array}$ & Hepatic \\
\hline Naloxone & $60-90 \mathrm{~min}$ & $\begin{array}{l}\text { Intravenous, intramuscular, } \\
\text { subcutaneous }\end{array}$ & $\begin{array}{l}100 \% \text { intravenous, intramuscular, } \\
\text { subcutaneous }\end{array}$ & $\begin{array}{l}\text { Renal } 70 \% \text {, } \\
\text { biliary 30\% }\end{array}$ & Hepatic \\
\hline Methadone & $15-60 h$ & Oral, intravenous & $\begin{array}{l}80 \% \text { oral, } \\
100 \% \text { intravenous }\end{array}$ & $\begin{array}{l}\text { Renal 70\%, } \\
\text { biliary 30\% }\end{array}$ & Renal, hepatic \\
\hline
\end{tabular}

a. Note that naloxone is not the same as naltrexone. Naltrexone is an orally active opioid antagonist used in tablet form to promote abstinence in opioid dependence and, more recently, in alcohol dependence.
Suboxone is a proprietary combination of the opioid partial agonist buprenorphine and the opioid antagonist naloxone ${ }^{\mathrm{a}}$ (Fiellin 2006). Suboxone tablets are taken sublingually because the active agent, buprenorphine, is not orally active. By contrast, naloxone is not active when taken sublingually or orally. Naloxone is only active when given parentally, usually intravenously after heroin overdose. The rationale for this product is that there was significant diversion and injecting of buprenorphine preparations. For example, a study of over 500 patients in Australia estimated that around 9\% injected their buprenorphine and almost 25\% had sold their buprenorphine in the previous year (Winstock 2008). Injecting Suboxone can precipitate extremely uncomfortable acute opioid withdrawal due to the presence of naloxone (this does not occur when the combination is taken sublingually or orally). Hence, the buprenorphinenaloxone combination is less likely to be injected, although it still has the capacity to be diverted onto the black market (Fiellin 2006).

A 24-week randomised open-label controlled trial involving 1267 opioid-dependent patients in the USA showed higher treatment retention using methadone (74\%) than buprenorphine-naloxone (46\%, a quarter of whom withdrew in the first 30 days) (Hser 2013).

Problems associated with buprenorphine include precipitated opioid withdrawal at induction, unpleasant taste and the inconvenience of supervised consumption of the sublingual tablets (which may take $10 \mathrm{~min}$, compared with perhaps $2 \mathrm{~min}$ for an oral methadone mixture). Buprenorphine (a partial agonist) will also attenuate the effects of illicit heroin more than methadone.

Around a third of both the methadone and buprenorphine-naloxone groups in Hser et al's study tested positive for opioids on weekly urine drug testing. It was unclear whether the patients who dropped out were also followed up using urine drug testing. The main problem in interpreting the results of this trial is that retention rates were reported as a surrogate for effectiveness. However, the data do not actually indicate whether there was any difference in effectiveness as shown by opioidpositive urine samples (presumably those patients who dropped out of the buprenorphine-naloxone arm subsequently started methadone, although it is unclear whether they were then followed up).

A 6-month randomised controlled trial (RCT) involved 24-day double-blind induction of 96 patients onto buprenorphine-naloxone or methadone, followed by the option of flexible dosing of buprenorphine-naloxone or escalation from buprenorphine-naloxone to methadone (Kakko 2007). Seventy-eight per cent of participants were retained for the 6 months, and half (46\%) of those who had started on buprenorphine-naloxone remained on this. At 6 months, opioid-positive urine samples had fallen to $20 \%$ in both arms (although by this point around three-quarters were on methadone).

\section{Buprenorphine monotherapy}

In practice, opioid-dependent people often have experienced both forms of buprenorphine and methadone medication and have a preference for one or the other that it is sensible to respect. For example, the SUMMIT trial involved a cohort, naturalistic study of 361 opioid-dependent people in England (Pinto 2010). This showed that two-thirds chose methadone and, although those taking methadone were twice as likely to remain in treatment over 2 years, those taking buprenorphine were twice as likely to produce opioid-free drug tests and achieve detoxification.

A Cochrane review concluded that flexible dosing regimes (where the patient elects to increase or decrease medication dose - typical 
of usual practice) showed a modest improvement in retention rates using methadone rather than buprenorphine (Mattick 2008). This was based on 8 studies involving 1068 participants. However, there was no difference between the two treatments in relation to suppression of illicit opioid use as determined by opioid-positive drug tests.

\section{Naltrexone}

The orally active opioid antagonist naltrexone can be used to block the effects of opioids in patients who are completely detoxified: it will precipitate severe acute opioid withdrawal if detoxification is not complete.

Meta-analyses of 13 randomised studies involving over 1000 patients produced inconclusive results for oral naltrexone (Minozzi 2011). Naltrexone implants have become available because poor adherence is a common problem with oral naltrexone, particularly in opioid-dependent people (in the Minozzi review, less than a third of patients remained in treatment - the trials had an average duration of 6 months). A double-blind RCT involving 70 heroin-dependent people over 6 months (Hulse 2009) reported that patients on oral naltrexone lapsed to heroin use sooner than those with the naltrexone implant (115 v. 158 days over 180-day follow-up). A Cochrane review in 2008 reported that there was one randomised trial of naltrexone depot in 60 opioid-dependent patients over 8 weeks, which compared two dosages of naltrexone injections (192 and $384 \mathrm{mg}$ ) with placebo (Comer 2006; Lobmaier 2008). Both depots significantly increased days in treatment, although the higher dose produced better results - the average time in treatment was 48 days with high-dose naltrexone v. 27 days on placebo. Retention in treatment at 56 days was $68.2 \%$, $60.0 \%$ and $38.9 \%$ of participants in the high-dose, low-dose and placebo groups respectively.

Cohort studies have reported that some parenteral formulations reduce mortality in opioid-dependent patients compared with oral naltrexone. Unfortunately, overall effectiveness in opioid and alcohol use disorders of naltrexone depots has yet to be demonstrated beyond highly motivated research samples.

\section{Dihydrocodeine}

Dihydrocodeine was first synthesised about 100 years ago (around the same time as heroin). It has been used for many decades, mostly in primary care, for treatment of opioid dependence. It is safe and cheap. Dihydrocodeine has been widely used for symptomatic relief from opioid withdrawal in settings where methadone is unavailable, such as police cells and emergency admission wards outside office hours. One of the most interesting research reports of recent years shows dihydrocodeine to be as effective as methadone in treatment of opiate dependence. An open-label trial involving 235 opiate-dependent patients over 42 months showed no difference in results between maintenance on dihydrocodeine and methadone, including retention in treatment (Robertson 2006). At 12 months, the retention rates were virtually identical (exceeding 80\%). Eight secondary outcomes were measured, including total illicit opioid use, reported crime, physical health, mental health, injecting drug use, overdoses, selling drugs and being in education or work. All secondary outcomes also showed significant, comparable improvement in both groups, although these were reported as composite scores.

Unfortunately, the patent for dihydrocodeine expired long ago so there is little incentive for pharmaceutical companies to promote this agent. Large quantities of dihydrocodeine tablets are required with frequent dosing - leading to risk of diversion (although dihydrocodeine has a high therapeutic index and low illicit value). Similarly, dihydrocodeine lacks any great novelty, as it has long been used in primary care in opioid dependence - unlike injectable opioids, for example. The UK Department of Health's clinical guidelines for substance misuse (Department of Health (England) 2007) show little enthusiasm for dihydrocodeine, despite its advantages. Hence uptake of dihydrocodeine as a treatment for opioid dependence is likely to be slow.

\section{Lofexidine}

Lofexidine is an alpha-2 adrenoreceptor agonist that acts peripherally (it does not cross the bloodbrain barrier so it avoids the central effects of clonidine). Lofexidine is not an opiate, nor is it addictive. It has been widely used in opioid detoxification and has largely replaced clonidine. Unfortunately, lofexidine can produce hypotension, so its use requires blood pressure monitoring. Lofexidine is given four times a day, typically over a 12-day course. By comparison, similar outcomes can be achieved using buprenorphine over a 7-day course with once-daily dosing (although buprenorphine is a controlled drug and can be misused). For example, Raistrick et al (2005) reported an open-label trial of buprenorphine and lofexidine for detoxification in heroin dependence. Of the 210 participants, $46 \%$ of those on lofexidine and $65 \%$ of those on buprenorphine completed detoxification, and $36 \%$ of the lofexidine and $46 \%$ of the buprenorphine groups reported abstinence 
at 1 month. The main advantage of lofexidine is that it can be stored and administered by staff without the requirement for special controlled drugs regulations.

\section{Slow-release oral morphine}

Slow-release oral morphine has been used in some small trials, particularly for patients intolerant of methadone because of cardiac arrhythmia (although buprenorphine and dihydrocodeine are also available). A randomised non-inferiority trial involving 157 patients showed no significant difference in outcomes between methadone and morphine (Beck 2014). Slow-release oral morphine is available as an alternative to methadone treatment in Austria, Slovakia, Slovenia, Bulgaria and Luxembourg.

A recent Cochrane review (Ferri 2013) of slowrelease oral morphine was inconclusive as there were only nine published trials, seven had no control group and only one, by Eder et al, was randomised. Eder et al (2005) reported a randomised, doubleblind study of 64 opioid-dependent people over 14 weeks comparing slow-release morphine (mean dose $680 \mathrm{mg}$ ) with methadone (mean dose $85 \mathrm{mg}$ ). There was no significant difference in outcomes such as retention rates (86\%) or illicit drug use, although there were fewer anxiety and physical symptoms in the morphine group.

In general, the results of trials suggest that slowrelease oral morphine has similar effectiveness to methadone in the short term, although an Austrian study (Beer 2010) indicated high rates of injecting and diversion of morphine tablets and this medication is therefore generally discouraged.

\section{Injectable opioid treatment}

UK guidelines on injectable opioid treatment were published in 2003 by the National Treatment Agency for Substance Misuse. Estimates suggest that around $10 \%$ of patients fail to benefit from optimised oral methadone treatment (or other more conventional treatment). There have been several studies of prescribed injectable heroin (diamorphine) from countries including Switzerland, Portugal, Holland, Germany and Canada. These culminated in the UK randomised injectable opioid treatment trial (RIOTT) of injectable heroin, injectable methadone and oral methadone (42-43 patients per group) with a 6-month follow-up (Strang 2010). Treatment involved twice-daily supervised self-administered injectables (typically 300-600 mg diamorphine per day up to $900 \mathrm{mg}$ maximum). All patients, including those on injectables, received oral methadone. The successful outcome was taken as half of the weekly urine samples being negative for illicit heroin (detected by impurities) in the final 3 months. Drop-out rates were low, at around $20 \%$, and $72 \%$ of patients on injectable heroin had a successful outcome, compared with $39 \%$ on injectable methadone and $27 \%$ on oral methadone. A further analysis of data from this trial (Byford 2013) suggested that injectable opioid treatment was more cost-effective than oral methadone (mean cost per participant over 6 months: injectable heroin, $£ 8995$; injectable methadone, $£ 4674$; oral methadone, £2596). However, when the costs of criminal activity were included, oral methadone was the most expensive treatment of the three (mean cost per participant over 6 months: injectable heroin, $£ 13410$; injectable methadone, £10945; oral methadone, £15805). Regrettably, relapse to illicit heroin use is common if injectable opioid treatment is discontinued even after prolonged periods.

Injectable opioids are probably the most controversial option for treatment of opioid dependence. The robust RIOTT trial convincingly demonstrated a potential saving of $£ 10000$ per year by prescribing injectable heroin for treatmentrefractory addiction. Injectable opioid treatment is expensive, at 4-5 times the cost of oral methadone treatment. The cost could be reduced significantly by relaxing the requirement to supervise selfadministration, although this would be at the risk of significant diversion.

\section{Stimulants for adults with ADHD and comorbid substance use disorder}

This topic was recently reviewed in Advances by Magon \& Müller (2012). Attention-deficit hyperactivity disorder (ADHD) affects $3-7 \%$ of children. It is characterised by the core signs of inattention, hyperactivity and impulsiveness. Childhood ADHD persists into adulthood in around 20\% of individuals (in adults it also known as attention-deficit disorder). A significant proportion of children with ADHD are not diagnosed and therefore an appreciable number of patients present to adult mental health services with undiagnosed ADHD. Between 25 and 50\% of patients attending adult mental health and substance misuse services fulfil diagnostic criteria for adult ADHD, compared with around $4 \%$ of the adult population. However, there has been particular concern regarding the indiscriminate treatment of mild to moderate ADHD with stimulant medication, especially in children.

Formal assessment of adult $\mathrm{ADHD}$ often requires patients to abstain from illicit drugs for 1 month. They should abstain for 3 months before starting 
treatment for ADHD - a criterion that is difficult to achieve, particularly with stimulant users.

\section{Evidence base for stimulants in childhood ADHD}

Stimulants, especially methylphenidate, have been of proven effectiveness in children and remain first-line treatment despite a long history of controversy (National Institute for Health and Clinical Excellence 2008). Stimulant therapy is also recommended as first-line treatment for adults with ADHD (Nutt 2007). Unfortunately, the risk of misuse and diversion of methylphenidate is of particular concern in patients with preexisting substance use disorders. Around 30\% of treatment-seeking adult cocaine users and $20 \%$ of opioid users met criteria for ADHD as children (Magon 2012).

Wilens et al (2008) reviewed 21 studies (involving over 100000 children and adolescents) assessing the diversion and misuse of stimulants (primarily methylphenidate) prescribed for ADHD. Reported rates of past-year use of diverted prescribed stimulants were 5-9\% in US school-age children and $5-35 \%$ in college students. Between 16 and $29 \%$ of students who were in receipt of a stimulant prescription had been asked to give, sell or trade their medication, and around $25 \%$ of college students had sold some of their prescribed stimulants. Slow-release formulations may reduce the risk of misuse and diversion of medication. The review revealed several longitudinal studies suggesting that treatment with stimulants reduces the risk of substance use disorders in individuals with ADHD, although some of these trials and/or their authors were supported by the pharmaceutical industry.

\section{Pharmacological treatment of ADHD in patients with substance use disorders}

Most trials of methylphenidate exclude patients with substance use disorders. A meta-analysis of ten trials of ADHD treatment for adults with substance use disorders reported an overall effect size approaching zero (Koesters 2009). This included four trials involving methylphenidate. However, there was a reduction in cocaine use. A randomised trial of 54 offenders with ADHD and amphetamine dependence showed modest improvement in ADHD symptoms and reduction in illicit drug use (Konstenius 2014).

Amphetamine has not been formally reported as a treatment for ADHD in adults with substance use disorders. Pemoline and modafinil have been reported, but the results of these small trials are not robust. Atomoxetine, a non-stimulant related to antidepressants, is an effective treatment for ADHD and it is not prone to misuse. Unfortunately, there are no formal trials of atomoxetine for ADHD with comorbid substance use disorders. Nevertheless, the lack of misuse potential suggests it in preference to stimulant drugs, although adherence is likely to be much less than with stimulants. There are two probable reasons for this lower adherence. First, stimulants are reported to be more effective than other, non-addictive, drugs in treatment of ADHD (Nutt 2007; NICE 2008). Second, experience with methadone, buprenorphine and naltrexone cited earlier clearly shows that drugs with addictive properties retain patients more effectively than those without. Stimulants such as methylphenidate are therefore likely to be more effective than antidepressants such as atomoxetine for adult $\mathrm{ADHD}$, although there is a significant potential for abuse and diversion. Bupropion (an antidepressant often used in smoking cessation) has been shown to be effective in at least four trials for ADHD with comorbid substance use disorders (Koesters 2009). For example, one open label trial involving 14 adolescent boys showed a $43 \%$ improvement in scores on the ADHD Symptom Checklist at 6 months.

A combination of bupropion and cognitivebehavioural therapy (CBT) would be a reasonable first-line approach for ADHD and substance use disorders. If stimulants are used in this context, measures similar to those for the use of opioids for non-cancer pain are recommended. For example, illicit drug testing, prescribing contracts specifying the duration of prescription and non-response criteria, objective measures of improvement, regular review, frequent dispensing of small quantities, a single prescriber and single pharmacy.

\section{Methylphenidate for substance misuse}

In the trials in which methylphenidate has been used for the treatment of stimulant misuse the results are disappointing. For example, a randomised doubleblind controlled trial of supervised slow-release methylphenidate involving 79 patients over 20 weeks showed no difference between the active and placebo groups regarding amphetamine-positive urine drug screens (90\% v. 95\%) and low retention rates (44\% v. 26\%) (Miles 2013).

\section{Alcohol dependence}

There is a major difference in practice between trials of treatments for alcohol dependence and for opioid dependence (Table 2), as there are drug treatments that are already proven to be highly effective in opioid dependence (methadone maintenance being the best example). Consequently, it is more difficult to support use of abstinence-based treatments in 
opioid dependence and researchers (and clinicians) have less incentive to promote these.

\section{Supervised disulfiram}

Disulfiram was discovered in the 1920s and has been used as a treatment for alcohol misuse since 1948. It prevents the breakdown of alcohol by acetaldehyde dehydrogenase. This leads to accumulation of acetaldehyde, causing headache, flushing, palpitations, nausea and vomiting. In general, trials of unsupervised disulfiram, both orally or as implants, have produced unimpressive results: several reviews and meta-analyses indicate no significant benefit for unsupervised disulfiram in alcohol use disorders (Johnsen 1991; Hughes 1997; Suh 2006).

Disulfiram has been combined with CBT in treatment of alcohol dependence. However, the most effective responses are obtained when disulfiram is supervised by a relative or other individual (Chick 1992). In this controlled trial, 126 patients were randomised to placebo or supervised disulfiram. Abstinent days were increased from 69 (38\%) to $100(55 \%)$ over 6 months. Alcohol use was reduced by $70-80 \%$ in the disulfiram group, compared with $50 \%$ in placebo. Just over half of the patients complied with the protocol.

Reports from 13 clinical trials of disulfiram for treatment of alcoholism suggest that supervised disulfiram was equal to naltrexone and/or acamprosate (Krampe 2010). For example, in one trial the time to first relapse (the consumption of more than five UK standard drinks or $40 \mathrm{~g}$ of alcohol in one day) occurred at a mean of 123 days with disulfiram, compared with 71 days with acamprosate (de Sousa 2005). This involved 93 participants randomised between the two medications over 8 months. Disulfiram produced 201 days of abstinence, compared with 169 days for acamprosate. Liver function tests confirmed the improvement in the disulfiram group. Similarly, an open randomised trial of 100 participants comparing disulfiram and naltrexone showed 306 v. 243 days of abstinence respectively over the 12-month period (de Sousa 2004). First relapse occurred at a mean of 119 days with disulfiram and at 63 days with naltrexone. Once again, liver function tests supported this improvement in the disulfiram group. In both trials, the participants were alcohol-dependent men undergoing private alcohol detoxification in Mumbai, India. These results are impressive and provide concrete support for the use of disulfiram, although they only generalise to patients from high social groups with good social support.

Disulfiram has been used in the treatment of alcohol problems for 60 years. Many trials since the 1980s have provided equivocal support for

TABLE 2 Descriptions and properties of some drugs used in treatment of alcohol dependence

\begin{tabular}{|c|c|c|c|}
\hline Drug & Action & Common side-effects & Information \\
\hline Disulfiram & $\begin{array}{l}\text { Aversive agent in alcohol dependence: } \\
\text { causes headache, nausea and flushing in } \\
\text { combination with alcohol }\end{array}$ & $\begin{array}{l}\text { Nausea, fatigue and lethargy. } \\
\text { Occasionally death following alcohol } \\
\text { poisoning. Potentially fatal: acute } \\
\text { hepatotoxicity in about } 1 \text { in } 25000 \\
\text { patients }\end{array}$ & $\begin{array}{l}\text { Once daily dosing. More effective when } \\
\text { supervised by third party. } \\
\text { Can only be started when abstinent. } \\
\text { Contraindicated in suicidality and severe } \\
\text { personality disorder }\end{array}$ \\
\hline Acamprosate & $\begin{array}{l}\text { Reduces craving (NNT around 7) in alcohol } \\
\text { dependence }\end{array}$ & $\begin{array}{l}\text { Benign side-effect profile, with occasional } \\
\text { diarrhoea, nausea, vomiting }\end{array}$ & Thrice daily dosing \\
\hline Naltrexone & $\begin{array}{l}\text { Orally active opioid receptor antagonist } \\
\text { to promote abstinence in alcohol } \\
\text { dependence (NNT around 9) and opioid } \\
\text { dependence }\end{array}$ & $\begin{array}{l}\text { Mainly gastrointestinal (diarrhoea, } \\
\text { nausea, vomiting). Once daily dosing. }\end{array}$ & $\begin{array}{l}\text { Precipitates severe opioid withdrawal } \\
\text { in opioid dependence: must be started } \\
\text { during abstinence from opioids }\end{array}$ \\
\hline Naloxone & $\begin{array}{l}\text { Intravenously active opioid antagonist } \\
\text { used in opioid overdose }\end{array}$ & Acute opiate withdrawal & Half-life: $60-90 \mathrm{~min}$ \\
\hline Nalmefene & $\begin{array}{l}\text { Orally active opioid receptor antagonist } \\
\text { used in alcohol dependence }\end{array}$ & $\begin{array}{l}\text { Nausea, insomnia, dizziness, headache } \\
\text { and vomiting }\end{array}$ & Similar to naltrexone. Once daily dosing \\
\hline Baclofen & $\begin{array}{l}\text { Antispasmodic used to promote } \\
\text { abstinence in alcohol dependence }\end{array}$ & $\begin{array}{l}\text { Confusion, dizziness, drowsiness, lethargy } \\
\text { and gastrointestinal disturbances, dry } \\
\text { mouth; hypotension, respiratory or } \\
\text { cardiovascular depression }\end{array}$ & $\begin{array}{l}\text { Related to benzodiazepine but GABA-B } \\
\text { receptor agonist (rather than GABA-A). } \\
\text { May cause withdrawal symptoms on } \\
\text { sudden withdrawal. } \\
\text { Thrice daily dosing }\end{array}$ \\
\hline Pabrinex $^{\circledR}$ & $\begin{array}{l}\text { i.v. or i.m. vitamin mixture containing } \\
\text { thiamine (vitamin } B_{1} \text { ) used prophylactically } \\
\text { to prevent Wernicke-Korsakoff syndrome }\end{array}$ & Pain and irritation at injection site & $\begin{array}{l}\text { Two or three times daily injections during } \\
\text { alcohol detoxification until potential } \\
\text { neurological symptoms resolve. } \\
\text { Occasional anaphylaxis so resuscitation } \\
\text { facilities required }\end{array}$ \\
\hline
\end{tabular}

i.m., intramuscular; i.v., intravenous; NNT, number needed to treat.

Source: British National Formulary (Joint Formulary Committee 2014). 
its effectiveness. However, as indicated above, disulfiram is a useful agent mostly for patients who are motivated and have appropriate supervision. A Cochrane review of seven controlled studies involving randomisation of 492 cocaine-dependent patients to disulfiram showed no significant benefit over placebo or naltrexone (Pani 2010).

\section{Nalmefene}

Nalmefene is an orally active opioid receptor antagonist like naltrexone. The manufacturers claim that it reduces alcohol consumption in people who continue to drink, particularly those who do not have physical withdrawal symptoms. Side-effects include nausea, insomnia, dizziness, headache and vomiting.

Mason et al (1999) recruited alcohol-dependent out-patients directly from the community rather than from treatment settings - individuals with seriously deranged liver function tests were excluded. The trial involved 105 individuals who remained abstinent for 2 weeks and were then randomised to one of two doses of nalmefene or to placebo over 12 weeks (84 days). Participants had typically consumed 8 US standard drinks per day ( 80 UK units per week) prior to treatment. Selfreported drinking or abstinence was confirmed objectively by breath alcohol concentration and also from collateral reports. Relapse was defined as 6 standard drinks on one day. At the end of the trial the odds ratio of relapsing to heavy drinking was 2.4 times greater with placebo than with nalmefene ( $60 \%$ v. $40 \%$ from the survival curves). The number of days until first relapse was 33 in the placebo group and 46 in the nalmefene group. However, relapses typically lasted, on average, for 0.9-1.5 days, so there was no significant difference in the total number of days abstinent. Thus, despite the apparently impressive outcome for nalmefene, the placebo group actually performed better in terms of the number of days abstinent ( 83 days out of 84 for the placebo v. 80 out of 84 days for nalmefene; or $99 \%$ v. $95 \%$ days of abstinence). At $86 \%$, medication adherence was highly unusual compared with that for typical treatment populations, probably owing to the recruitment process (direct from the community). There was no difference in biochemical liver enzyme values between groups at the end of treatment ( $25 \%$ reduction).

Three trials from the manufacturer of namalfene have been submitted to the European regulator, but only one of these (ESENSE 1) has been published in full. ESENSE 1 was a 6 -month double-blind placebo-controlled trial of nalmefene involving 604 patients without physical alcohol dependence (Mann 2013). The drop-out rate was high (50\% of the treatment group). Patients consumed an average of $84 \mathrm{~g}$ of alcohol per day prior to intake. At the end of 6 months, the number of heavy drinking days ( $>6$ units per day for men) was $12 \%$ less in the nalmefene group (the placebo group reduced from 20 to 11 heavy drinking days per month or $45 \%$; the nalmefene group reduced from 19 to 8 heavy drinking days per month, a reduction of $58 \%$. Overall the difference was $\sim 2$ heavy drinking days per month. Total alcohol consumption was lower in the nalmefene group (placebo group reduced from 85 to $45 \mathrm{~g}$ alcohol per day or 47\%; the nalmefene group reduced from 84 to $33 \mathrm{~g}$ alcohol per day or $61 \%)$. Changes in liver enzyme values were not published in the paper.

\section{Baclofen}

Baclofen is a metabotropic gamma-aminobutyric acid $\left(\mathrm{GABA}_{\mathrm{B}}\right)$ receptor agonist (benzodiazepines are ionotropic $\mathrm{GABA}_{\mathrm{A}}$ receptor agonists). Baclofen is used to treat muscle spasms, particularly after spinal injuries. It can produce a withdrawal syndrome similar to benzodiazepines. Higher doses can produce sedation and ataxia, while overdose may produce sedation, coma, symptoms similar to neuroleptic malignant syndrome and seizures. A typical therapeutic dose in alcohol dependence ranges from 30 to $80 \mathrm{mg} /$ day.

In a 12 -week RCT of baclofen, 146 individuals with heavy alcohol dependence reported abstinence rates of $29 \%$ in the placebo and $71 \%$ in the baclofen group (relapse was defined as more than 4 drinks per day) (Addolorato 2007). There was a modest improvement in liver function scores in the treatment group. However, no benefit was reported in a comparable 8-week trial involving 76 patients (25\% heavy drinking days during the trial for both groups; Garbutt 2010). Consequently, the benefits of baclofen remain to be confirmed. The effect of baclofen may be related to its anxiolytic activity.

\section{Naltrexone/acamprosate and the COMBINE project}

The COMBINE study involved 1383 patients with alcohol dependence randomised, following detoxification, to nine separate combinations of naltrexone, acamprosate and a combined behavioural intervention (CBI) for 3 months (Anton 2006). Eight of the groups also received a brief intervention from the prescribing physician; the ninth group received only CBI. Half of the participants were randomised to the CBI (up to 20 1-hour sessions), although this had no additional benefit relative to monotherapy with active medication. During treatment, all groups reduced their alcohol consumption. The eight 
MCO answers

$\begin{array}{lllll}1 b & 2 b & 3 c & 4 c & 5 a\end{array}$ groups receiving combinations of pills, medical management and CBI had $74-81 \%$ of days abstinent. The CBI-only group (with no pills or medical brief intervention) responded relatively poorly (66\% of days abstinent). Acamprosate had no significant effect. The overall effects were smaller but persisted at 1 year. Once the effect of an active placebo is taken into account, it is unlikely that the results of the COMBINE project produced any clinically significant outcomes - indeed, one of the principal results seems to highlight the placebo effect of contact with a prescribing physician for a brief intervention regardless of whether a placebo tablet or an active medication is used.

The COMBINE study was very large and produced disappointing results. However, other meta-analyses of smaller trials have supported use of both anti-craving drugs (naltrexone and acamprosate) to prevent relapse in alcohol misuse. Their support is qualified, as adherence was often low and the overall benefits were modest at best (Bouza 2004). A number needed to treat of 7.5 for acamprosate was derived from a meta-analysis of 17 randomised trials involving 4087 patients (Mann 2004). This reported continuous abstinence rates at 6 months as being significantly higher in the acamprosate-treated patients (acamprosate, $36 \%$; placebo, 23\%). A further Cochrane review of 24 RCTs involving 6915 patients supported the use of acamprosate (Rösner 2011). By comparison, a Cochrane review of 50 studies involving 7793 patients using the opioid antagonists naltrexone or nalmefene gave a number needed to treat of 9 for naltrexone in alcohol dependence (Rösner 2010).

\section{Conclusions}

Although methadone has come under increased scrutiny due to electrocardiogram abnormalities and high death rates from overdose of diverted prescriptions, the higher cost of supervised consumption and inconvenience of the principal alternative (buprenorphine and its combination with naloxone) probably prevent methadone being relegated to a second-line treatment for opioid dependence. Widespread use of high-dose dihydrocodeine seems unlikely without aggressive marketing by pharmaceutical companies. Research on the use of stimulants to treat adult ADHD is proceeding, although the risks of misuse and diversion by people with addictive disorders are a major problem.

Evidence to support the effectiveness of medication in promoting alcohol abstinence remains disappointing, despite large trials of naltrexone and acamprosate. However, there is some encouraging research to support use of supervised disulfiram with people who have good social support.
Disulfiram has been used for 60 years and it seems unlikely that it would remain in use, despite its obvious side-effects, if it were not recognised to be effective by clinicians. Research on other agents, such as baclofen and nalmefene, continues.

\section{References}

Addolorato G, Leggio L, Ferrulli A, et al (2007) Effectiveness and safety of baclofen for maintenance of alcohol abstinence in alcohol-dependent patients with liver cirrhosis: randomised, double-blind controlled study. Lancet, 370: 1915-22.

Anton RF, O'Malley SS, Ciraulo DA, et al (2006) Combined pharmacotherapies and behavioral interventions for alcohol dependence: the COMBINE study. A randomized controlled trial. JAMA, 295: 2003-17.

Beck T, Haasen C, Verthein U, et al (2014) Maintenance treatment for opioid dependence with slow-release oral morphine: a randomized crossover, non-inferiority study versus methadone. Addiction, 109: 617-26.

Beer B, Rabl W, Libiseller K, et al (2010) [Impact of slow-release oral morphine on drug abusing habits in Austria] [article in German]. Neuropsychiatry, 24: 108-17.

Bouza C, Angeles M, Muñoz A, et al (2004) Efficacy and safety of naltrexone and acamprosate in the treatment of alcohol dependence: a systematic review. Addiction, 99: 811-28.

Byford S, Barrett B, Metrebian N, et al (2013) Cost-effectiveness of injectable opioid treatment v. oral methadone for chronic heroin addiction. British Journal of Psychiatry, 203: 341-9.

Chick J, Gough K, Falowski W, et al (1992) Disulfiram treatment of alcoholism. British Journal of Psychiatry, 161: 84-9.

Comer SD, Sullivan MA, Yu E, et al (2006) Injectable, sustained-release naltrexone for the treatment of opioid dependence: a randomised, placebo-controlled trial. Archives of General Psychiatry, 63: 210-8.

Davoli M, Bargagli AM, Perucci CA, et al (2007) Risk of fatal overdose during and after specialist drug treatment: the VEdeTTE study, a national multi-site prospective cohort study. Addiction, 102: 1954-9.

Department of Health (England) and the devolved administrations (2007) Drug Misuse and Dependence: UK Guidelines on Clinical Management. Department of Health (England), Scottish Government, Welsh Assembly Government and Northern Ireland Executive.

de Sousa A, de Sousa A (2004) A one-year pragmatic trial of naltrexone vs disulfiram in the treatment of alcohol dependence. Alcohol and Alcoholism, 39: 528-31.

de Sousa A, de Sousa A (2005) An open randomized study comparing disulfiram and acamprosate in the treatment of alcohol dependence. Alcohol and Alcoholism, 40: 545-8.

Eder $\mathrm{H}$, Jagsch R, Kraigher D, et al (2005) Comparative study of the effectiveness of slow-release morphine and methadone for opioid maintenance therapy. Addiction, 100: 1101-9.

Ferri M, Minozzi S, Bo A, et al (2013) Slow-release oral morphine as maintenance therapy for opioid dependence. Cochrane Database of Systematic Reviews, 6: CD009879.

Fiellin DA, Pantalon MV, Chawarski MC, et al (2006) Counseling plus buprenorphine-naloxone maintenance therapy for opioid dependence. New England Journal of Medicine, 355: 365-74.

Garbutt JC, Kampov-Polevoy AB, Gallop R, et al (2010) Efficacy and safety of baclofen for alcohol dependence: a randomized, double-blind, placebo-controlled trial. Alcoholism: Clinical and Experimental Research, 34: 1849-57.

Hser YI, Saxon AJ, Huang D, et al (2013) Treatment retention among patients randomized to buprenorphine/naloxone compared to methadone in a multi-site trial. Addiction, 109: 79-87.

Hughes JC, Cook CC (1997) The efficacy of disulfiram: a review of outcome studies. Addiction, 92: 381-95.

Hulse GK, Morris N, Arnold-Reed D, et al (2009) Improving clinical outcomes in treating heroin dependence: randomized, controlled trial of oral or implant naltrexone. Archives of General Psychiatry, 66: 1108-15. 
Joint Formulary Committee (2014) British National Formulary (68). BMJ Group \& Pharmaceutical Press.

Johnsen J, Mørland J (1991) Disulfiram implant: a double-blind placebo controlled follow-up on treatment outcome. Alcoholism, Clinical and Experimental Research, 15: 532-6.

Kakko J, Grönbladh L, Svanborg KD, et al (2007) A stepped care strategy using buprenorphine and methadone versus conventional methadone maintenance in heroin dependence: a randomized controlled trial. American Journal of Psychiatry, 164: 797-803.

Koesters M, Becker T, Killian R (2009) Limits of meta-analysis: methylphenidate in the treatment of adult ADHD. Psychiatric Clinics of North America, 23: 733-44.

Konstenius M, Jayaram-Lindström N, Guterstam J, et al (2014) Methylphenidate for attention deficit hyperactivity disorder and drug relapse in criminal offenders with substance dependence: a 24-week randomized placebo-controlled trial. Addiction, 109: 440-9.

Krampe H, Ehrenreich H (2010) Supervised disulfiram as adjunct to psychotherapy in alcoholism treatment. Current Pharmaceutical Design, 16: 2076-90.

Lobmaier P, Kornor H, Kunoe N, et al (2008) Sustained-release naltrexone for opioid dependence. Cochrane Database of Systematic Reviews, 2 : CD006140

Luty J (2003) What works in drug addiction? Advances in Psychiatric Treatment, 9: 280-8.

Luty J (2006) What works in alcohol use disorders? Advances in Psychiatric Treatment, 12: 13-22.

Luty J (2014) Drug and alcohol addiction: new challenges. Advances in Psychiatric Treatment, 20: 413-21.

Magon R, Müller U (2012) ADHD with comorbid substance use disorder: review of treatment. Advances in Psychiatric Treatment, 18: 436-46.

Mann K, Lehert P, Morgan MY (2004) The efficacy of acamprosate in the maintenance of abstinence in alcohol-dependent individuals: results of a meta-analysis. Alcoholism: Clinical and Experimental Research, 28 : 51-63.

Mann K, Bladström A, Torup L, et al (2013) Extending the treatment of options in alcohol dependence: a randomized controlled study of asneeded nalmefene. Biological Psychiatry, 73: 706-13.

Mason BJ, Salvato FR, Williams LD (1999) A double-blind placebo controlled study of oral nalmefene for alcohol dependence. Archives of General Psychiatry, 56: 719-24.

Mattick RP, Kimber J, Breen C, et al (2008) Buprenorphine maintenance versus placebo or methadone maintenance for opioid dependence. Cochrane Database of Systematic Reviews, 2: CD002207.

Miles SW, Sheridan J, Russell B, et al (2013) Extended-release methylphenidate for treatment of amphetamine/methamphetamine dependence: a randomized, double-blind, placebo-controlled trial. Addiction, 108: 1279-86.
Minozzi S1, Amato L, Vecchi S, et al (2011) Oral naltrexone maintenance treatment for opioid dependence. Cochrane Database of Systematic Reviews, 4: CD001333.

National Institute for Health and Clinical Excellence (2008) Attention Deficit Hyperactivity Disorder: Diagnosis and Management of ADHD in Children, Young People and Adults (NICE Clinical Guideline 72). NICE.

National Treatment Agency for Substance Misuse (2003) Injectable Heroin (and Injectable Methadone): Potential Roles in Drug Treatment. Full Guidance Report. National Treatment Agency.

Nutt DJ, Fone K, Asherson P, et al (2007) Evidence-based guidelines for management of attention-deficit/hyperactivity disorder in adolescents in transition to adult services and in adults: recommendations from the British Association for Psychopharmacology. Journal of Psychopharmacology, 21: 10-41

Pani PP1, Trogu E, Vacca R, et al (2010) Disulfiram for the treatment of cocaine dependence. Cochrane Database of Systematic Reviews, 1: CD007024.

Pinto H, Maskrey V, Swift L, et al (2010) The SUMMIT Trial: a field comparison of buprenorphine versus methadone maintenance treatment. Journal of Substance Abuse Treatment, 39: 340-52.

Raistrick D, West D, Finnegan 0, et al (2005) A comparison of buprenorphine and lofexidine for community opiate detoxification: results from a randomized controlled trial. Addiction, 100: 1860-7.

Robertson JR, Raab GM, Bruce M, et al (2006) Addressing the efficacy of dihydrocodeine versus methadone as an alternative maintenance treatment for opiate dependence: a randomized controlled trial. Addiction, 101: 1752-9.

Rösner S, Hackl-Herrwerth A, Leucht S, et al (2010) Naltrexone and nalmefene for alcohol dependent patients. Cochrane Database of Systematic Reviews, 12: CD001867.

Rösner S, Hackl-Herrwerth A, Leucht S, et al (2011) Acamprosate for alcohol dependent patients. Cochrane Database of Systematic Reviews, 9: CD004332.

Strang J, Metrebian N, Lintzeris N, et al (2010) Supervised injectable heroin or injectable methadone versus optimised oral methadone as treatment for chronic heroin addicts in England after persistent failure in orthodox treatment (RIOTT): a randomised trial. Lancet, 375: 1885-95.

Suh JJ, Pettinati HM, Kampman KM, et al (2006) The status of disulfiram: a half of a century later. Journal of Clinical Psychopharmacology, 26 290-302.

Wilens TE, Adler LA, Adams J, et al (2008) Misuse and diversion of stimulants prescribed for ADHD: a systematic review of the literature. Journal of the American Academy of Child \& Adolescent Psychiatry, 47 : 21-31.

Winstock AR, Lea T, Sheridan J (2008) Prevalence of diversion and injection of methadone and buprenorphine among clients receiving opioid treatment at community pharmacies in New South Wales, Australia. International Journal of Drug Policy, 19: 450-8.

\section{MCOs}

Select the single best option for each question stem

1 The active agents contained in the recently introduced sublingual combination preparation for treatment of opioid dependence are:

a buprenorphine and naltrexone

b buprenorphine and naloxone

c buprenorphine and codeine

d codeine and paracetamol

e dihydrocodeine and paracetamol.

\section{Which of the following agents is orally active?}

a buprenorphine

b naltrexone

\section{c naloxone}

d buprenorphine-naloxone combination

e endogenous opioid peptides.

\section{Dihydrocodeine was first synthesised:}

a 30 years ago

b 50 years ago

c 100 years ago

d 200 years ago

e 800 years ago.

4 Lofexidine and clonidine are agonists at:

a cholinergic receptors

b nicotinic receptors

c alpha-2 adrenergic receptors d serotonin receptors

e dopamine receptors.

5 Disulfiram:

a is most effective when supervised

b exerts its principal therapeutic action as an agonist at mu-opioid receptors

c prevents breakdown of methadone

d was discovered in the 1970s

$\mathrm{e}$ is recommended for substance-dependent patients with severe personality disorders. 